\title{
Sexual violence cases in a hospital setting in Hong Kong: victims' demographic, event characteristics, and management
}

\author{
WK Chiu, WC Lam *, NH Chu, Charles KM Mok, WK Tung, Frances YL Leung, SM Ting
}

\section{A B S T R A C T}

Introduction: Rainlily, the first one-stop crisis centre in Hong Kong, was set up in 2000 to protect female victims of sexual violence. This study aimed to analyse the characteristics of sexual assault cases and victims who presented to two hospitals in Hong Kong. The data are invaluable for health care professionals and policymakers to improve service provision to these victims.

Methods: This retrospective analysis of hospital records was conducted in two acute hospitals under the Hospital Authority in Hong Kong. Sexual assault victims who attended the two hospitals between May 2010 and April 2013 were included. Characteristics of the cases and the victims, the use of alcohol and drugs, involvement of violence, and the outcome of the victims were studied.

Results: During the study period, 154 sexual assault victims attended either one of the two hospitals. Their age ranged from 13 to 64 years. The time from assault to presentation ranged from 1 hour to more than 5 months. Approximately $50 \%$ of the assailants were strangers. Approximately $50 \%$ of victims presented with symptoms; the most common were pelvic and genitourinary symptoms. Those with symptoms (except pregnancy) presented earlier than those without. The use of alcohol and drugs was involved in $36.4 \%$ and $11.7 \%$ of cases, respectively.

This article was published on 24 Oct 2016 at www.hkmj.org.
Approximately $10 \%$ of the screened victims were positive for Chlamydia trachomatis. There were 11 pregnancies with gestational age ranged from 6 weeks to 5 months at presentation. Less than half of the victims completed follow-up care.

Conclusions: Involvement of alcohol and drugs is not uncommon in sexual assault cases. Efforts should be made to promote public education, enhance coordination between medical and social services, and improve the accessibility and availability of clinical care. Earlier management and better compliance with follow-up can minimise the health consequences and impact on victims.

\section{Hong Kong Med J 2016;22:576-81 \\ DOI: $10.12809 / \mathrm{hkmj} 164970$}

\author{
WK Chiu, MB, ChB, MRCOG \\ ${ }^{1}$ WC Lam *, MRCOG, FHKAM (Obstetrics and Gynaecology) \\ ${ }^{2} \mathrm{NH}$ Chu, MRCP (UK), FHKAM (Emergency Medicine) \\ ${ }^{1}$ CKM Mok, FRCOG, FHKAM (Obstetrics and Gynaecology) \\ ${ }^{2}$ WK Tung, FRCSEd, FHKAM (Emergency Medicine) \\ ${ }^{3}$ FYL Leung, FHKAM (Emergency Medicine) \\ ${ }^{3}$ SM Ting, FRCSEd, FHKAM (Emergency Medicine)
}

Department of Obstetrics and Gynaecology, United Christian Hospital, Kwun Tong, Hong Kong

${ }^{2}$ Department of Accident and Emergency, Kwong Wah Hospital, Yaumatei, Hong Kong

${ }^{3}$ Department of Accident and Emergency, United Christian Hospital, Kwun Tong, Hong Kong

This paper was presented at the 2015 Western Pacific Regional Conference of Medical Women's International Association, 24-26 April 2015, Taipei, Taiwan.

* Corresponding author: lam_mona@hotmail.com

New knowledge added by this study

- A significant proportion of sexual assault cases involved the use of alcohol (36.4\%) or drugs (11.7\%). This number may be underreported. Physical violence with or without verbal threat was reported in approximately $30 \%$ of cases. Half of the victims attended hospital more than 3 days after the incident when emergency contraception would be less effective.

Implications for clinical practice or policy

- Blood and urine samples for toxicology screening should be obtained in selected sexual assault cases. Public education should focus on primary prevention, the means of seeking help, and the importance of early medical care. A territory-wide case review may offer a better evaluation of the problem in Hong Kong.

\section{Introduction}

Sexual violence refers to sexual activity where consent is not obtained or freely given. ${ }^{1}$ The World Health Organization defines sexual violence as "any sexual act, attempt to obtain a sexual act, or other act directed against a person's sexuality using coercion, by any person regardless of their relationship to the victim, in any setting". This includes rape, indecent assault, sexual harassment and threats. According to the statistics of 'Child abuse, spouse/cohabitant 
battering and sexual violence cases' from the Social Welfare Department, the majority (88.4\%) of newly reported sexual violence cases in Hong Kong are indecent assault and $8.8 \%$ are rape or unlawful sexual intercourse. More than $96 \%$ of the victims are females. Approximately $70 \%$ of the perpetrators are strangers, and the rest are usually someone known to the victim, such as a family member, friend, lover or ex-lover, co-worker, caregiver, neighbour, or teacher. ${ }^{3}$ Sexual violence is usually underreported because of fear: fear of physical examination, disclosure of sexual history, repeating the traumatic experience in full detail over and over again, complicated legal procedures, not being believed by others, and being harmed by the perpetrator(s). ${ }^{2}$

Sexual violence may lead to health consequences such as unwanted pregnancy, sexually transmitted disease (STD) infections, physical trauma, depression, and post-traumatic stress disorder. ${ }^{4}$ Not all victims will seek medical care, however, because the experience of sexual violence is seen as stigmatising and shameful, with possible extreme social consequences. ${ }^{5}$ Stigmatisation not only from society but also from health care providers, family, and even the intimate partner is common. This leads to minimal support for the victims who may distance themselves by withdrawing from social activities. ${ }^{6}$

In November 2000, the Association Concerning Sexual Violence Against Women set up the first onestop crisis centre in Hong Kong, Rainlily, for the protection of female victims of sexual violence. All the social workers at Rainlily are female and trained to provide counselling and care for victims of sexual assault. They will accompany the victim for medical care, police interviews, legal proceedings, and most importantly, the possibly long and difficult recovery period from the incident.

For many years, Rainlily has worked with the accident and emergency department of Kwong Wah Hospital to provide one-stop service to victims of sexual violence including pregnancy prevention, screening and prevention of STDs, forensic medical examination, psychological support, and reporting to the police if desired by the victim. This avoids recalling and repeating the unpleasant experience for different professionals and hence minimises the need for the victim to psychologically re-live the trauma. Since May 2010, Rainlily has also collaborated with the United Christian Hospital and set up an additional rape crisis centre.

We conducted a retrospective analysis of female victims of sexual assault who were seen at either hospital to evaluate the characteristics of the cases and the victims, the use of alcohol and drugs, involvement of violence, and the outcome of the victims. The data are invaluable for health care professionals and policymakers for improving service provision for victims.

\section{於香港醫院就診的性暴力受害者的人口學數據、 事件特徵和處理}

趙韻琴、林慧翔、朱雁鴻、莫嘉明、董偉杰、梁玉鸞、陳素梅

引言：風雨蘭於 2000 年成立, 是香港首間專為遭受性暴力的女性提供 一站式援助的機構。本研究旨在分析於香港兩間醫院就診的性暴力受 害女性的特徵。研究結果可讓醫護人員和醫療決策者參考, 改善給予 受侵害婦女的服務。

方法: 本研究回顧分析香港轄下兩間急症醫院紀錄。研究範圍包括 2010 年5月至 2013 年4月期間曾到該兩間醫院就診的性暴力個案及受 害女性。分析案件和受害人的特點、酒精和毒品的使用、暴力介入, 以及受害人的臨床結果。

結果 : 研究期間共有 154 名性暴力受害婦女到該兩間醫院就診, 年齡 介乎13至64歲。從事故發生至就診時間介乎1小時至5個多月不等。個 案中約有 $50 \%$ 施襲者為陌生人。約有一半受害者出現症狀, 主要為盆 腔及泌尿生殖問題。具症狀的受害者（不包括懷乃）比沒有症狀的受 害者較早就診。牽涉酒精的個案有 $36.4 \%$, 牽涉藥物的個案有 $11.7 \%$ 。 約有 $10 \%$ 受害者感染沙眼衣原體。就診時已懷孕的有 11 例, 孕期介乎 6周至5個月。只有不足一半的受害者完成覆診和跟進。

結論：牽涉酒精和毒品的性侵害案件屢見不鮮。應積極推行公眾教 育、加強醫療和社會服務間的協調, 以及改善和有效落實有關之臨床 服務。及早處理個案和提高覆診跟進的依從性可以減少事件對受害者 健康的影響。

\section{Methods}

All female sexual assault victims who attended the Kwong Wah Hospital or United Christian Hospital from May 2010 to April 2013 were included in this retrospective study. The sexual assault cases were identified from the special case list of the accident and emergency department of each hospital and the designated gynaecology clinic booking list of the United Christian Hospital. The clinical records were reviewed and the demographics of the victims, time lapse from assault to presentation at hospital, characteristics of the assault, investigations and results, treatment and outcome of the victims were analysed.

At Kwong Wah Hospital, the sexual assault cases were managed and followed up in the accident and emergency department, with referral to gynaecologists if clinically indicated, for example, for unwanted pregnancy. At the United Christian Hospital, cases were initially managed in the accident and emergency department with subsequent followup in the gynaecology clinic. At initial presentation, victims were screened for the presence of any infection, including STDs. Emergency contraception was prescribed if necessary. Subsequent follow-up was after 2 weeks, 6 weeks, 3 months, and 6 months to exclude pregnancy, to review investigation results 
and treat any infection.

The study protocol complied with the good clinical practice of $\mathrm{ICH}$ (The International Conference on Harmonisation of Technical Requirements for Registration of Pharmaceuticals for Human Use). Ethical approval was obtained from Clinical Research Ethics Committee of Hospital Authority.

All statistical analysis of data was performed by PASW Statistics 18, Release Version 18.0.0 (SPSS, Inc, 2009, Chicago [IL], US). For continuous data with a highly skewed distribution such as time from the incident of assault to presentation at the hospital, Mann-Whitney $U$ test was used. The critical level of statistical significance was set at 0.05 .

\section{Results}

\section{Demographics of victims}

From May 2010 to April 2013, a total of 154 sexual assault victims had attended either hospital; 102 at Kwong Wah Hospital and 52 at United Christian Hospital. The age of victims ranged from 13 to 64 years (mean 24.5 years, median 22 years; Table 1). Most (150 cases; $97.4 \%)$ victims were Chinese and four were domestic helpers from other Asian countries. Five (3.2\%) victims were mentally disabled and 19 (12.3\%) had a history of psychiatric disorder.

\section{Time between assault and presentation}

The time from the incident of assault to presentation at the hospital ranged from 1 hour to more than 5 months (mean 16 days, median 3 days). Half of the victims $(n=77)$ attended hospital within 3 days of the incident. Approximately half $(n=84,54.5 \%)$ of the assailants were strangers (Table 2); the others included friend, internet friend, family member, classmate, colleague, employer, boyfriend, exboyfriend, and ex-husband.

The median time from the incident to presentation was 48 hours (interquartile range [IQR], 24-240 hours) for victims with symptoms (except pregnancy), compared with 288 hours for those without (IQR, 48-696 hours) $[\mathrm{P}<0.001]$. Those who were pregnant (median time, 756 hours; IQR, 510-1386 hours) presented later than those who were not (median time, 72 hours; IQR, 24-432 hours) $[\mathrm{P}<0.001]$.

\section{Characteristics of the incident}

In $56(36.4 \%)$ cases, alcohol was involved in the incident. There were $18(11.7 \%)$ cases where drugs were involved, including ketamine, amphetamine, methamphetamine, cocaine, and midazolam. In one victim, multiple drugs were involved. Some victims could not identify which drug they had been given. It had either been added to the victim's drink, or been given as 'flu medication' or an 'anti-drunk pill'.
TABLE I. Age distribution of victims $(n=154)$

\begin{tabular}{lc}
\hline Age-group (years) & No. (\%) of victims* \\
\hline$<18$ & $37(24.0)$ \\
$18-25$ & $59(38.3)$ \\
$26-35$ & $41(26.6)$ \\
$36-45$ & $12(7.8)$ \\
$>45$ & $5(3.2)$ \\
\hline Because of rounding, the percentages do not total 100
\end{tabular}

TABLE 2. Time of presentation*

\begin{tabular}{ccccc}
\hline & \multicolumn{4}{c}{ Time of presentation } \\
\cline { 2 - 5 } & $\mathbf{3}$ Days & $\mathbf{5 1}$ Week & $\mathbf{5 1}$ Month & $\mathbf{> 1}$ Month \\
\hline Assailant & & & & \\
Known & 33 & 6 & 19 & 10 \\
Unknown & 44 & 7 & 20 & 13 \\
Pregnancy & & & & \\
Yes & 1 & 0 & 4 & 5 \\
No & 76 & 13 & 35 & 18 \\
\hline
\end{tabular}

* Information about the time from the incident of assault to presentation at hospital was not available in 2 cases

There were 133 (86.4\%) victims with documented vaginal penetration, of whom 25 had also been exposed to oral penetration, five to anal penetration, and four to all three forms of sexual assault. There were three victims in whom penetration was oral only. The remaining 18 victims had no clear documentation. In only three (1.9\%) cases did the assailant use a condom. Verbal threats were reported by six (3.9\%) victims, and physical violence with or without verbal threat by 45 (29.2\%). Reported physical violence included restraint, strangling, beating, grasping, and biting.

\section{Presenting symptoms}

Apart from the incident, 75 (48.7\%) victims presented with other associated problems, most $(n=44,28.6 \%)$ with pelvic or genitourinary symptoms such as lower abdominal pain, vaginal discharge, or urinary symptoms. There were $17(11.0 \%)$ victims who complained of laceration, contusions, bruises, and pain due to physical violence during the incident. Another 12 (7.8\%) victims presented with psychiatric or mood problems: two attempted suicide, one had auditory hallucinations, and the others had mood problems or post-traumatic stress disorder with nightmares and flashbacks. One victim presented with per rectal bleeding due to anal penetration and another presented with recurrent oral ulcers in which oral penetration was involved during the incident. Seven victims had found themselves pregnant before attending the hospital. 


\section{Sexually transmitted diseases}

Blood testing for hepatitis B surface antigen was performed in 146 victims of whom six (4.1\%) were positive. All positive results were obtained within 6 weeks of the sexual assault. Hepatitis B surface antibodies were not present in 85 of 134 victims tested. Hepatitis B immunoglobulin was given to 43 victims and a first dose of hepatitis $B$ vaccination to 52. Only 29 victims completed the course of hepatitis $B$ vaccination, however, and the remainder defaulted from follow-up.

Blood test for syphilis by rapid plasma reagin was positive in one victim and was performed around 4 days after the sexual assault. Treponema pallidum haemagglutination assay was also positive. There was no other positive case in the subsequent screening at 6 weeks and 6 months. A similar result was obtained when testing for anti-hepatitis C virus antibody that was positive in one victim and the test was performed within 1 day of the sexual assault. There was no other positive case identified at subsequent follow-up. Blood tests for anti-human immunodeficiency virus antibody were all negative and a total of 71 victims had negative serology 6 months after the alleged assault.

High vaginal and endocervical swabs were taken for culture and revealed one victim with Trichomonas vaginalis. Urethral, rectal, and throat swabs were taken in selected cases and no infection other than with Candida species was detected. Chlamydia trachomatis was tested by polymerase chain reaction test on a urine sample or endocervical swab in 110 victims, and 12 (10.9\%) were positive. Among those with chlamydial infection, four presented with genitourinary symptoms such as perineal pain, vaginal discharge, urinary frequency, and dysuria.

\section{Pregnancy}

Emergency contraception was provided to 63 of the 77 victims who presented within 3 days of the alleged rape. There were 10 victims who had been prescribed emergency contraception, either by other doctors, or self-prescribed from a pharmacy. Other reasons for not prescribing emergency contraception included a victim with only oral penetration, one victim with a previous hysterectomy, two victims taking reliable regular contraception, and one victim who refused the prescription.

There were a total of 11 pregnancies as a result of the incident, among them one victim had received emergency contraception within the day of assault. The gestational age ranged from 6 weeks to 5 months at presentation. Eight cases underwent termination of pregnancy, one underwent medical evacuation for silent miscarriage, one continued the pregnancy to term, and one defaulted from follow-up with unknown outcome.

\section{Attendance at follow-up}

Attendance at follow-up was 57.8\%, 63.6\%, 59.1\% and $46.8 \%$ at 2 weeks, 6 weeks, 3 months, and 6 months, respectively after the incident. Overall, less than half of the victims completed follow-up care.

\section{Discussion}

Every 2 to 3 minutes, one woman is sexually assaulted somewhere in the world. ${ }^{7}$ The prevalence of sexual violence differs across populations, but studies have consistently shown there to be underreporting in both developed and developing countries. ${ }^{5}$ It is believed that Hong Kong is no different. The reported cases may only be the tip of the iceberg. This makes prevention, detection, and proper care difficult.

Comparison with a similar study conducted in Hong Kong from 2001 to 2004 by Chu and Tung ${ }^{8}$ shows that the age of victims, time between assault and presentation, and the percentage of those lost to follow-up are similar; thus the characteristics appear unchanged over the past decade. This raises the question of whether we are doing enough to promote awareness, prevention, and education in society.

A considerable proportion of victims have a history of psychiatric disorder, and there is emerging evidence of the association. ${ }^{9}$ Although the causal relationship is not well understood, it might be due to the higher prevalence of alcohol or substance abuse among this population. Nonetheless, a history of alcohol or substance abuse was not always documented in the case notes. Patients having a certain type of psychiatric disorder-such as schizophrenia, bipolar disorder, and heroin addiction-are more likely to adopt risky behaviour, ${ }^{10}$ and hence are at higher risk of being sexually abused.

The delayed presentation among victims of assault by a known assailant may be due to the fear of being discovered by the assailant and being further harmed. Furthermore, sexual violence is associated with stigma in some communities, even in cases with an unknown assailant; the victims may be afraid of being blamed, and there is also a perceived lack of support from families and friends. ${ }^{11}$ Delayed presentation may result in loss of forensic evidence, delay in prescription of STD prophylaxis, and a missed chance for emergency contraception. ${ }^{12}$ This explains why those who were pregnant presented later than those who were not, and those without symptoms may not have sought help until they found themselves pregnant. Public education definitely has a role and must emphasise the importance of seeking medical care early and promote community awareness of prevention, instead of blaming the victims.

The prevalence of sexual assault involving alcohol or drug use in this study was similar to a 
previous study by Hurley et al. ${ }^{13}$ Females are more vulnerable to the effects of alcohol because of their smaller body mass and higher proportion of body fat. Compared with drugs, there is a higher rate of alcohol involvement in sexual assault cases because it is easily available, cheap, and legally and socially acceptable. Alcohol can cause disinhibition and impair judgement; most of the victims consumed alcohol voluntarily and therefore there is a strong feeling of self-blame after the incident. Recreational drugs consumed by victims themselves or 'date rape drug'-spiked drinks given to victims can cause sedation, anterograde amnesia, and incapacitation. The actual prevalence is likely to be more than reported, as the victims may not be aware of the assault or only have patchy recall of events. Some of these victims have an intense fear of internet exposure of their body or the incident, and feel a loss of control and sense of insecurity. If a drug abuser is assaulted, they may worry about being charged and are reluctant to report the incident to the police. Delay in reporting or seeking help results in loss of forensic evidence and delay in prescription of emergency contraception. The current protocol of the two studied units did not include toxicological analysis. Therefore the drug used was based on the victim's report and recall error is highly likely. In order to improve service provision and to help in crime recollection, blood, urine, and nasal swabs for toxicology screening should be obtained in selected sexual assault cases. Public education should emphasise the harmful effects of excessive alcohol consumption and the effects of combining alcohol and recreational drugs. Ways to avoid spiked drinks include keeping an eye on one's drink, not leaving a drink unattended or obtaining a new one if it is, and not accepting a drink from strangers.

The most common presenting symptoms were pelvic and genitourinary symptoms or injuries as a result of violence during the incident. Psychiatric symptoms were usually underreported. Common symptoms include low mood, fear, guilt, nervousness, sleeping difficulties, poor appetite, and feelings of shame and anger. Emotional numbness and avoidance are common reasons for not seeking help. ${ }^{14}$ Moreover, some medical providers do not actively ask about psychiatric symptoms. Even if symptoms are reported, they may be considered a 'normal reaction' to rape and then ignored. About half of victims recover from acute psychological effects by 12 weeks, but in others the symptoms persist for years. ${ }^{14}$ Sexual assault survivors are at increased lifetime risk of post-traumatic stress disorder, major depression, suicidal ideas and attempts. ${ }^{15}$ Mental state and risk of self-harm should be assessed to identify those who are at risk. Psychosocial support and opportunities to talk about the incident are important. For those who do not recover with time, referral to a psychotherapist or even a psychiatrist is essential.

Some experts discourage testing for STD infections in the acute setting unless clinically indicated by symptoms. ${ }^{15}$ The positive rate of STD in this study was low with the exception of chlamydial infection. Nucleic acid amplification testing can be carried out on urine samples instead of endocervical samples, minimising the need for invasive vaginal examination using a speculum. ${ }^{14}$ One may consider omitting the screening test and instead offering prophylactic antibiotics against bacterial STDs.

The rate of pregnancy $(7.1 \%)$ is slightly higher than the quoted risk of $5 \% .{ }^{16}$ The administration of emergency contraception in the two studied units comes in the form of levonorgestrel and was limited to victims who presented within 3 days of alleged rape. Levonorgestrel is licensed for up to 72 hours after unprotected intercourse, indeed there is still some residual efficacy after 3 days although it diminishes with time. To further decrease the chance of pregnancy, other contraceptive methods can be considered in victims who present more than 3 days after the incident, including a copper intrauterine device or ulipristal acetate. If it is not feasible to insert an intrauterine device in the emergency department, urgent referral to a gynaecology clinic should be considered. Ulipristal acetate may not be readily available in all public hospitals but it could be stocked and prescribed as a patient-financed item.

Limitations of this study include the small sample size, recall bias of alcohol or drug use, loss of some victims to follow-up, and short follow-up periods. A territory-wide case review may offer a better evaluation of the problem in Hong Kong.

\section{Conclusions}

Sexual assault is usually underreported and can lead to significant health consequences. Involvement of alcohol and drugs is not uncommon in sexual assault cases. Efforts should be made to enhance coordination and cooperation between medical and social services, and improve the accessibility and availability of clinical care. Health care professionals should be properly trained to understand the physical and mental health consequences, the importance of follow-up care, and to equip the skills to manage sexual assault cases. Public education should target at primary prevention, and publicise the simple ways to access the available services.

\section{Acknowledgement}

The authors gratefully acknowledge Mr Edward Choi for his valuable statistical advice.

\section{Declaration}

All authors have disclosed no conflicts of interest. 


\section{References}

1. Understanding sexual violence. National Center for Injury Prevention and Control, Centers for Disease Control and Prevention; 2012.

2. Violence against women: preventing intimate partner and sexual violence against women. Geneva: World Health Organization; 2011.

3. Statistics on child abuse, spouse/cohabitant battering and sexual violence cases. Social Welfare Department, the Government of the Hong Kong Special Administrative Region; 2014.

4. Welch J, Mason F. Rape and sexual assault. BMJ 2007;334:1154-8.

5. Dartnall E, Jewkes R. Sexual violence against women: the scope of the problem. Best Pract Res Clin Obstet Gynaecol 2013;27:3-13.

6. Jina R, Thomas LS. Health consequences of sexual violence against women. Best Pract Res Clin Obstet Gynaecol 2013;27:15-26.

7. Masho SW, Odor RK, Adera T. Sexual assault in Virginia: A population-based study. Womens Health Issues 2005;15:157-66.

8. Chu LC, Tung WK. The clinical outcome of 137 rape victims in Hong Kong. Hong Kong Med J 2005;11:391-6.

9. Goodman LA, Rosenberg SD, Mueser KT, Drake RE.
Physical and sexual assault history in women with serious mental illness: prevalence, correlates, treatment, and future research directions. Schizophr Bull 1997;23:68596.

10. Hariri AG, Karadag F, Gokalp P, Essizoglu A. Risky sexual behavior among patients in Turkey with bipolar disorder, schizophrenia, and heroin addiction. J Sex Med 2011;9:2284-91.

11. Abrahams N, Devries K, Watts C, et al. Worldwide prevalence of non-partner sexual violence: a systematic review. Lancet 2014;383:1648-54.

12. McCall-Hosenfeld JS, Freund KM, Liebschutz JM. Factors associated with sexual assault and time to presentation. Prev Med 2009;48:593-5.

13. Hurley M, Parker H, Wells DL. The epidemiology of drug facilitated sexual assault. J Clin Forensic Med 2006;13:1815.

14. Cybulska B. Immediate medical care after sexual assault. Best Pract Res Clin Obstet Gynaecol 2013;27:141-9.

15. Linden JA. Clinical practice. Care of the adult patient after sexual assault. N Engl J Med 2011;365:834-41.

16. Holmes MM, Resnick HS, Kilpatrick DG, Best CL. Raperelated pregnancy: estimates and descriptive characteristics from a national sample of women. Am J Obstet Gynecol 1996;175:320-4. 